\title{
Editorial Dossiê
}

\section{Ocupações urbanas no Brasil contemporâneo}

\author{
Urban occupations in contemporary Brazil
}

http://dx.doi.org/10.5007/2178-4582.2015v49n1p116

Os Ocupas se impuseram no cenário mundial recente como formas de protesto e reação à crise contemporânea do capitalismo, re-colocando em cena a ação direta como estratégia de luta e de protesto. Mas bem antes disto, em países da periferia do capitalismo, a estratégia da ocupação de terras já era o principal recurso usado por muitos movimentos sociais latino-americanos, entre os quais se destaca o Movimento Sem-Terra, no Brasil. Modo concreto de enfrentamento ao latifúndio e ao Estado no atendimento de preceitos legais que proclamam - mas adiam, permanentemente - a função social da propriedade, a estratégia radical da ocupação, com a consigna "ocupar, resistir, produzir", foi apropriada pelos movimentos urbanos que, sobretudo nos últimos anos, parecem ter adquirido certo protagonismo das lutas sociais no Brasil. A reivindicação do direito à moradia e à terra urbana, na esteira dos movimentos populares que emergiram no contexto da redemocratização, prosseguiu articulando vários setores progressistas, inspirados pela noção de direito à cidade, ao longo das últimas décadas, tendo como ponto importante o Estatuto da Cidade, em 2001. Assim como seus predecessores, estas ocupações, quando organizadas podem ser consideradas movimentos - na medida em que se radicalizam, passam a ser designados pelo discurso hegemônico como sendo "invasores" e "criminosos", tal qual o Movimento Sem-Terra, justificando despejo e repressões violentas.

O massacre de Pinheirinho em 2012, na cidade de São Paulo, pode ser considerado como um momento emblemático não no que tange ao uso da repressão e da violência, moedas correntes do aparato estatal diante dos pobres, no Brasil, mas pelo apoio político obtido de imediato de outros movimentos, sociais, com quem passam a estabelecer alianças. Entre estes aliados chama atenção a presença da juventude. Se as Jornadas de Junho (2013), as manifestações contra a Copa (2014) e as recentes lutas contra a terceirização expressam a reascensão das lutas sociais no país, ocupações urbanas organizadas e os movimentos sociais de luta pela moradia têm adquirido nesse cenário um papel central. Parece que no contexto urbano, a institucionalização de algumas demandas, a proliferação de projetos sociais e de programas de tipo 
assistencial e filantrópico, muitas vezes despolitizadoras, e o crescente "participativismo" e a "onguização" dos movimentos sociais não têm sido suficientes para conter a explosão do problema urbano (moradia, mobilidade, luta por parques e áreas públicas). Mesmo políticas públicas dignas de menção, como o programa Minha casa Minha Vida, carro-chefe da política habitacional dos governos petistas, têm sido bastante criticados por especialistas e pelos movimentos, em função dos limites que apresenta tanto em termos de seu formato quanto em termos de seu alcance. $\mathrm{O}$ déficit habitacional brasileiro continua elevado, diante dos processos de êxodo rural e deslocamentos regionais, que aumentam a concentração de trabalhadores e trabalhadoras em condições precarizadas de trabalho e de vida ao redor das grandes e médias cidades do país.

A resposta à chamada para este dossiê foi tão surpreendente quanto tem sido a explosão da questão da moradia na sociedade brasileira, nos últimos anos. Planejado inicialmente para acolher reflexões sobre as ocupações urbanas, esse dossiê acabou abrigando reflexões sobre os processos relacionados ao tema da moradia e da reforma urbana de uma forma mais ampla. Tal ampliação se justifica face à grande afluência de artigos e proposições que recebeu. Assim, os leitores e as leitoras terão acesso a reflexões de pesquisadores e pesquisadoras de várias universidades do país, acerca de temas que fazem parte da pauta dos movimentos sociais em luta pelo direito à moradia.

Neste primeiro conjunto de textos, os leitores encontrarão os artigos de Carlos Eduardo Nobre, trabalhando com a instigante Cartografia da Ação acerca da situação de Maceió, a uma primeira vista alvissareira, já que apresenta uma significativa diminuição do déficit habitacional; porém, o autor mostra que apesar de disposição dos movimentos para a negociação com o Estado e do recente aparato formal que repousa sobre a noção de função social da propriedade, as novas dinâmicas e processos ocorridos na região não alteraram de forma radical o acesso ao direito à cidade e à moradia. Além da análise dos movimentos de luta pela moradia e ocupações de Maceió, o autor mostra como os conceitos de vazios de urbanos e de domicílios vagos devem ser cautelosamente utilizados nas análises, pois se referem a situações empíricas diversas, motivo pelo qual o "caso " de Maceió nos ajuda a pensar sobre outras realidades. Levando em consideração a importância do trabalho da Fundação João Pinheiro, importante fonte de informações para quem se dedica ao tema, o autor chama atenção para algumas imprecisões contidas em conceitos como vazios urbanos e domicílios vagos. Nobre analisa o contraste entre a ausência de habitação (para a maioria) e a concentração de imóveis e de terras (para uma minoria), um argumento forte que contribui para a legitimidade social dos movimentos e das lutas pela moradia. Também destaca a diferença entre as noções de remoção e de reintegração de posse - bem 
conhecidas pelos moradores sem-teto - e as de remoção para realocação, empreendidas pelo Estado, recurso utilizado para realocar a população de assentamentos ou ocupações espontâneas. Através da cartografia dos deslocamentos das ocupações para os conjuntos, o autor demonstra como se dá, nos anos recentes, a reprodução da segregação socioespacial.

O segundo artigo, de Vitor Matheus de Oliveira Menezes, analisa as percepções de moradores do Jardim das Cajazeiras, acerca do programa Minha, casa, Minha Vida em Salvador. A análise da percepção dos moradores sobre este programa do governo federal, parte da noção de que as políticas públicas devem ser analisadas considerando a compreensão sobre o "mundo da vida dos entrevistados", tendo por foco o caso do Jardim das Cajazeiras. Apoiado em pesquisas oficiais sobre o programa, empreendidas pelo IPEA e Ministério das Cidades, mas também em dados coletados pelo autor no local, se pode concluir que não obstante o acesso à moradia garantido pelo PMCMV, os demais direitos que deveriam estar relacionados a este (incluindo o direito à cidade ou a uma "inclusão social") ainda estão longe de ser atingidos. Neste sentido, faz eco às criticas quanto à natureza do Programa - para além de sua insuficiência em termos quantitativos.

Já o artigo de Elaine Dorighello Tomás e Luis Fernando Scheibe trata do processo de re-territorialização de várias comunidades do Maciço do Morro da Cruz, em Florianópolis, muitas delas localizadas ema áreas de risco, e legalizadas como zonas especiais de interesse social, pela prefeitura da cidade. Esta área também foi contemplada pelo Programa de Aceleração do Crescimento (PAC), do governo federal, processo que envolveu o próprio movimento, mostrando neste caso a propensão dos movimentos populares e comunitários de negociar e agir muitas vezes em conjunto com o poder público - uma questão que tem gerado polêmicas e dissensos internos aos movimentos, e que podem estar compondo, junto a outros aspectos, o complexo processo de desarticulação destes atores. O artigo busca compreender até que ponto as políticas de reconhecimento dessa população, historicamente desconsiderada e invisibilizada, realmente propiciam a sua inclusão social, ou se conduziriam a processos de reterritorialização que reproduziriam, em novos moldes, a segregação sócio-espacial.

O artigo de Natália Cristina Batista e de Thiago Canettieri coloca em cena da ocupação Dandara, em Belo Horizonte, umas das maiores da região. Para tanto, utilizam fundamentalmente a narrativa oral obtida de um de seus moradores. A seleção dessa narrativa como fio condutor da análise é bastante interessante do ponto de vista metodológico, pois, como dizem seus autores, a história de Seu Orlando é emblemática de toda uma parcela da população que chegou à capital mineira nas últimas décadas em busca de melhorias em 
suas condições de vida e que se deparou com uma realidade diversa e adversa a suas expectativas. Mas, nesse cenário desolador, seu Orlando encontra os movimentos sociais, com os quais rapidamente se identifica e que passa a integrar, e que se colocam como importantes organizadores - objetivos e subjetivos - das experiências singulares destes sujeitos sociais.

Por fim, o artigo de José Eduardo Baravelli se detém no programa Minha Casa Minha Vida (PMCMV), que tem concentrado a atenção dos movimentos de luta por moradia no que tange à sua relação com as políticas habitacionais. $\mathrm{O}$ artigo parte de regulamentos de governo e estudos estatísticos para analisar o uso do conceito de déficit habitacional como legitimador institucional do programa de habitação do governo federal. Ao mostrar como o subsídio habitacional com fundos públicos da habitação para famílias de baixa renda, uma reivindicação histórica dos movimentos de luta por moradia, é apropriado pelas empresas construtoras, e não pelas famílias cadastradas pelo programa, o autor põe em relevo a discussão sobre as contradições entre o PMCMV, o Plano Nacional de Habitação (PlanHab, formulado no início da presidência Lula) e o movimento de Reforma Urbana. A análise dos resultados dessa política de subsídio relacionada ao déficit habitacional traz importantes reflexões sobre a forma como uma política econômica pode ser legitimada como programa habitacional.

Com essa primeira edição do dossiê buscamos contemplar uma diversidade de realidades regionais, retratando a multiplicidade de atores, situações, e constituição de campos de ação política. Ao mesmo tempo, procuramos também por em evidência diferentes perspectivas teóricas e metodológicas sob as quais a questão urbana pode ser refletida no Brasil contemporâneo. A sua organização expressa o desejo dos envolvidos em atuar de forma interinstitucional, no contexto de retomadas das lutas sociais no país, com as quais a universidade brasileira e as Ciências Humanas, de modo especial, têm um compromisso político histórico e urgente. Boa leitura!

Francisco Canella ${ }^{1}$

Carmen Susana Tornquist ${ }^{2}$

${ }^{1}$ Doutor em Ciências Sociais e Professor do Departamento de Ciências Humanas/ UDESC. E-mail: franciscocanella@hotmail.com

${ }^{2}$ Doutora em Antropologia e Professora do Programa de Planejamento da UDESC.

E-mail: carmentornquist@hotmail.com 